\title{
Programas de residência médica em oncologia orientados por competência: trajetória de uma construção coletiva
}

\author{
Eliana Claudia de Otero Ribeiro*
}

\section{Resumo}

O presente trabalho apresenta a trajetória de construção do Programa de Residência Médica em Cirurgia Oncológica orientado por competência, seu marco teórico e o produto final alcançado, aprovado pela Comissão Nacional de Residência Médica do Ministério de Educação em 2006. Trata-se de iniciativa inovadora no país, por introduzir nova abordagem à certificação profissional, aqui entendida como construção social. Nesse processo participaram ativamente representantes das esferas de gestão do SUS, prestadores de serviços, instituições formadoras e sociedades de especialistas, conferindo um carater de construção coletiva à iniciativa. Orienta-se pela perspectiva de regulação para a formação profissional em cancerologia, ao propor uma direcionalidade do perfil profissional de forma a atender às necessidades do Sistema Único de Saúde. Trata-se de iniciativa que confere às instâncias públicas decisórias sobre a residência médica, hoje responsáveis pelo financiamento da maior parte das bolsas de residência médica no país, uma alternativa para direcionar os programas de formação nas especialidades aos requerimentos de qualidade e relevância social exigidos pela sociedade e para inserir os demais atores envolvidos na regulação do exercício profissional nas iniciativas de avaliação, seguimento e controle da acreditação institucional para o desenvolvimento da residência médica em cancerologia no país.

Palavras-chave: Residência médica; Regulação de recursos humanos; Formação por competência.

*Doutora em Saúde Coletiva, docente do Núcleo de Tecnologia Educacional para a Saúde (NUTES/ UFRJ), Coordenadora de Ensino e Divulgação Científica do INCA. Considera-se aqui relatora da experiência, devendo todos os participantes listados nos apêndices A e C ser considerados coautores do trabalho. 


\section{INTRODUÇÃO}

O Conselho Consultivo do INCA, em sua reunião de fevereiro de 2005, pronunciou-se favoravelmente à criação de um Grupo de Trabalho (GT), voltado à questão de formação de recursos humanos para o controle do câncer no país.

O GT entendeu ser seu propósito construir legitimidade para a introdução de processos de pactuação de perfis profissionais na área de oncologia entre atores diversos envolvidos na formação, na regulação do exercício profissional e na prestação de assistência, de forma a assegurar o planejamento de programas de formação que atendam ao compromisso de excelência do cuidado exigido pela sociedade e a ser cumprido pelo SUS nas diferentes regiōes do país.

Entendeu o Conselho ser a primeira tarefa do referido grupo a construção de argumentos sólidos, assentados em metodologia de trabalho claramente definida, que orientassem o debate nacionalmente travado ao redor da duração de programas de residência médica em oncologia clínica e cirúrgica, de forma a responder ao compromisso inequívoco do INCA com a formação de profissionais competentes para atuarem em todos os níveis de cuidado na rede de atenção oncológica do país.

Tomando por base a diretriz de que as definições a serem tomadas devem resultar de debate e consenso a ser construído entre grupos e instituições envolvidos na formação de profissionais em oncologia no país, o INCA, em parceria com a SGETS/MS, convidou-os para definir e aprovar o plano de trabalho, proposto e organizado por meio de um ciclo de oficinas para a construção de programas de residência médica orientados por competência.

Com base nessa diretriz, teve lugar no INCA, Rio de Janeiro, em 31 de março de 2005, a $1^{\text {a }}$ Oficina do referido ciclo, na qual pactuaram-se a metodologia e o cronograma de trabalho. Foram definidos como objetivos da iniciativa: - Construir de forma pactuada o perfil de competência do Cancerologista Cirúrgico;

- Construir projeto político-pedagógico capaz de proporcionar as capacidades e o padrão de excelência delineados no perfil de competência;

- Fornecer subsídios para as políticas de formação e certificação nas especialidades oncológicas.

Identificaram-se critérios que pudessem permitir a seleção das instituições participantes, de forma a explorar a diversidade de olhares envolvidos na formação e exercício profissional nas diferentes macrorregiōes do país. Instituições prestadoras de serviços públicas, privadas e filantrópicas; sociedades de especialistas; instituições formadoras; instituições reguladoras do exercício profissional e gestores do SUS foram convocados a indicar profissionais cirurgiōes oncológicos que, a seu juízo, representassem o padrão de excelência que a instituição legitima. $\mathrm{O}$ apêndice $\mathrm{A}$ contém a lista das instituiçōes indicantes e os indicados.

Segundo a metodologia proposta, uma segunda oficina explorou as capacidades e áreas de competência de cirurgiōes oncológicos cuja prática refletia, segundo a visão de cada instituição indicante, o exercício profissional de excelência. A exploração das atividades desenvolvidas pelos cirurgiōes, de suas capacidades e do que consideravam como perfil de excelência - temas esses debatidos segundo contextos e cenários variados de exercício profissional - resultou na elaboração de um documento-síntese, composto por áreas de competência, ações-chave e desempenhos.

O perfil delineado na oficina 2 foi encaminhado a 62 cirurgiōes oncológicos no país, dos quais 32 retornaram suas contribuições ao formulário de validação enviado, sendo o índice de retorno considerado bastante satisfatório.

As sugestôes enviadas e o grau de concordância obtido em cada item foram cuidadosamente analisados e apresentados para reavaliação em uma nova planilha, onde apareciam, em destaque, as modificações sugeridas por diferentes validadores. Dessa segunda etapa de validação resultou o documento final (apêndice B), referente ao perfil profissional por competência do Cancerologista Cirúrgico.

O processo de trabalho que se seguiu a essas primeiras oficinas, um longo percurso de mais de um ano de duração, representou a união de esforços de todos os envolvidos na formação do Cancerologista Cirúrgico no país. Representantes de todas as dez Instituições Formadoras nessa área constituíram o "Grupo de Trabalho para os Programas de Residência Médica em Cancerologia Cirúrgica Orientados por Competência", em uma iniciativa pioneira na Residência Médica brasileira, de cooperação e apoio mútuos com vistas à reestruturação dos seus programas de Residência Médica, segundo um perfil de competência delineado coletivamente pelos envolvidos na Atenção Oncológica no país. Os membros constituintes do GT encontram-se no apêndice C.

\section{PRESSUPOSTOS METODOLÓGICOS}

As políticas nacionais de saúde e de educação apontam diretrizes orientadas para as mudanças dos 
processos de formação e de certificação profissional. Essas mudanças - e as Diretrizes Curriculares Nacionais são exemplarmente aqui citadas - foram produto de debates intensos entre diferentes atores e reafirmam para todos os envolvidos na formação de profissionais de saúde a necessidade de reconhecimento e de ampliação da responsabilidade social de que estão investidos e de uma repactuação para os processos de acreditação institucional, de definição de competência e de certificação profissional.

Os padrôes de competência utilizados para a certificação profissional explicitam o que o profissional deve saber e ser capaz de fazer para desempenhar sua prática em diferentes cenários com sucesso, possibilitando o desenvolvimento do profissionalismo ${ }^{1}$. Refletem, dessa maneira, os valores atribuídos, por uma sociedade, às capacidades que legitimam o exercício de uma determinada carreira ou especialidade e que, coerentemente, devem orientar os processos de formação e de avaliação de profissionais.

A orientação do currículo por competência sintetiza uma expressiva mudança nos pressupostos e na organização dos atuais cursos de formação para profissionais de saúde. Entretanto, em função da polissemia do termo competência, faz-se necessário explicitar-se a concepção aqui empregada, necessariamente imbricada nas questões relativas à educação profissional e à qualificação e, portanto, às políticas educacionais e de trabalho.

Propor a formação de profissionais capazes de desenvolver uma nova prática em saúde, comprometida com os princípios que regem o Sistema Único de Saúde implica, ao lado da definição de um novo perfil desejado, o aproximar-se dos elementos constitutivos desse novo fazer e pensar. Nesse sentido, impõe-se uma interlocução de saberes para a abordagem dos problemas relevantes das práticas sanitárias e de cuidado, regidas pelo princípio da interdisciplinaridade e pelo compromisso de construção sinérgica de novos objetos do conhecimento profissional e de práticas de intervenção em saúde, centrados nos princípios que regem o sistema de saúde do país.

Assim, ao lado dos conhecimentos científicos que conformam a base da ação profissional e lhe dão legitimidade, há que se considerar os interesses de diferentes atores que, de fato, com maior ou menor poder, explícita ou implicitamente, participam do processo de decisão e escolha dos saberes necessários e do perfil profissional requerido para o desenvolvimento de práticas de saúde, sabidamente orientadas por projetos político-ideológicos diversos ${ }^{2}$.

Destaca-se, assim, uma dimensão distintiva da competência profissional, reconhecendo que os processos de certificação de competências constituemse, em verdade, em instrumentos da sociedade para fazer com que certos saberes sejam reconhecidos socialmente, saiam da esfera do privado e ingressem na esfera do público, o que, de imediato, coloca a questão das competências no campo dos conflitos de interesse, relaçôes e hierarquias de poder na sociedade ${ }^{3}$.

A base distintiva da concepção de competência aqui empregada fundamenta-se na compreensão do currículo como produção social, do papel social da instituição formadora e das relaçôes que ela estabelece com a sociedade nessa produção. Nesse caso, em particular, cabe ressaltar o compromisso dos Centros de Alta Complexidade em Oncologia (CACON), hospitais de ensino e universitários, sede de programas credenciados de residência em oncologia, com a qualidade da atenção oncológica no SUS, base sobre a qual assentam-se programas de formação de excelência.

O reconhecimento da história das pessoas e da sociedade em seus processos de reprodução e de transformação da realidade e a escuta ampliada da perspectiva dos atores envolvidos na formação, no trabalho, na regulação e no consumo dos serviços prestados constituem-se na base da construção curricular orientada pela concepção dialógica de competência, base da iniciativa aqui relatada.

\section{A REESTRUTURAÇ̃̃O DOS PROGRAMAS DE RESIDÊNCIA MÉDICA EM CANCEROLOGIA CIRÚRGICA}

O perfil construído e validado do Cancerologista Cirúrgico foi analisado e discutido pelos representantes das Residências Médicas credenciadas em um terceiro encontro do ciclo de oficinas, no qual se constituiu o referido "Grupo de Trabalho para os Programas de Residência Médica em Cancerologia Cirúrgica Orientados por Competência". Essa oficina teve como objetivo caracterizar os ciclos de formação do Cancerologista Cirúrgico, necessários para alcançar o perfil proposto e, a partir daí, definir os conteúdos, cenários, experiências de ensino-aprendizagem em cada um dos ciclos de formação.

Considerando o perfil definido na oficina 2, foram analisadas áreas prioritárias de formação segundo a prevalência de tumores no país. Os estudos epidemiológicos colocam o câncer como um verdadeiro problema de saúde pública. Neste sentido, as últimas publicações do INCA delineiam uma realidade a ser necessariamente compreendida para o atendimento que 
a população demanda e, por conseguinte, considerada como base para as discussões no âmbito da formação.

No Brasil, as estimativas para 2006 apontam 472. 050 casos novos de câncer. Os tipos mais incidentes, à exceção de pele não-melanoma, serão os de próstata e de pulmão no sexo masculino e os de mama e de colo do útero no sexo feminino.
São esperados 234.570 casos novos para o sexo masculino e 237.480 para o sexo feminino distribuídos heterogeneamente nas unidades da federação do país. Observa-se uma grande variação regional na distribuição das taxas brutas de incidência de câncer, seja de uma forma geral ou por localização primária, conforme pode ser observado nas tabelas a seguir:

Tabela 1. Estimativas para o ano 2006 das taxas brutas de incidência por 100.000 e de número de casos novos por câncer, em homens e mulheres, segundo a região

\begin{tabular}{l|c|c|c|c}
\hline \multirow{2}{*}{$\begin{array}{c}\text { Localização Primária } \\
\text { Neoplasia maligna }\end{array}$} & \multicolumn{3}{c}{ Estimativa de Casos Novos } \\
\cline { 2 - 5 } & \multicolumn{2}{c}{ Estado } & \multicolumn{2}{c}{ Capital } \\
\cline { 2 - 5 } Traquéia, brônquio e pulmão & Casos & Taxa Bruta & Casos & 26,40 \\
Estômago & 17.850 & 19,41 & 5.300 & 19,68 \\
Próstata & 14.970 & 16,30 & 3.950 & 69,74 \\
Cólon e reto & 47.280 & 51,41 & 13.980 & 21,78 \\
Esôfago & 11.390 & 12,36 & 4.390 & 8,47 \\
Leucemias & 7.970 & 8,64 & 1.720 & 7,78 \\
Cavidade oral & 5.330 & 5,82 & 1.570 & 15,01 \\
Pele melanoma & 10.060 & 10,91 & 3.050 & 3,80 \\
Outras localizações & 2.710 & 2,92 & 830 & 91,45 \\
Subtotal & 61.530 & 66,92 & 18.370 & 264,63 \\
Pele não-melanoma & 179.090 & 194,77 & 53.160 & 68,13 \\
Todas as neoplasias & 55.480 & 60,74 & 13.680 & 332,62 \\
\hline
\end{tabular}

Fonte: Estimativas para o ano 2006 de número de casos novos de câncer, por região ${ }^{4}$

\begin{tabular}{l|c|c|c|c}
\hline \multirow{2}{*}{$\begin{array}{c}\text { Nocalização Primária } \\
\text { Neoplasia maligna }\end{array}$} & \multicolumn{3}{c}{ Estimativa de Casos Novos (MULHERES) } \\
\cline { 2 - 5 } & \multicolumn{2}{c}{ Estado } & \multicolumn{2}{c}{ Capital } \\
\cline { 2 - 5 } Mama feminina & Casos & Taxa Bruta & Casos & Taxa Bruta \\
\hline Traquéia, brônquio e pulmão & 48.930 & 51,66 & 17.900 & 13,38 \\
Estômago & 9.320 & 9,82 & 2.980 & 11,55 \\
Colo do útero & 8.230 & 8,65 & 2.610 & 27,11 \\
Cólon e reto & 19.260 & 20,31 & 6.030 & 24,09 \\
Esôfago & 13.970 & 14,73 & 5.370 & 2,43 \\
Leucemias & 2.610 & 2,74 & 600 & 6,08 \\
Cavidade oral & 4.220 & 4,45 & 1.360 & 4,92 \\
Pele melanoma & 3.410 & 3,58 & 1.130 & 4,02 \\
Outras localizações & 3.050 & 3,16 & 940 & 102,17 \\
Subtotal & 63.320 & 66,78 & 22.750 & 276,96 \\
Pele não-melanoma & 176.320 & 185,95 & 61.670 & 68,92 \\
Todas as neoplasias & 61.160 & 64,53 & 15.340 & 345,94 \\
\hline
\end{tabular}

Fonte: Estimativas para o ano 2006 de número de casos novos de câncer, por região ${ }^{4}$ 
Com base nessa análise epidemiológica foi construído o Quadro 1, que indica as áreas nas quais o cancerologista cirúrgico, com formação geral para o domínio das condiçôes prevalentes no país, deve desenvolver suas capacidades clínico-cirúrgicas.

Quadro 1. Áreas de formação do Cancerologista Cirúrgico

Tórax
Aparelho Geniturinário Masculino
Pele e Tecido Ósseo e Conectivo
Aparelho Reprodutor Feminino
Mama
Cabeça e Pescoço
Abdome e Pelve

A análise dos desempenhos delineados no perfil do Cancerologista Cirúrgico permite a compreensão de que esse profissional é um cirurgião generalista que, no diaa-dia da especialidade, executa procedimentos cirúrgicos de grande porte. Os relatos de coordenadores de Residência Médica dos hospitais A.C. Camargo e Erasto Gaertner reforçam a noção de um cirurgião cancerologista que, em seu exercício profissional, intervém nas diversas patologias tumorais nos diferentes sítios de localização em todo o corpo: os egressos das referidas instituições atuam, em sua maioria, como generalistas em cancerologia - freqüentemente como o único especialista de sua loco-região. Nesse sentido, entendendo que a autonomia desse profissional na prática é definida, centralmente, por sua expertise na condução de situações cirúrgicas de complexidade diversa, que exigem o desenvolvimento de outras capacidades de manejo clínico em suas múltiplas dimensões, o Grupo de Trabalho buscou definir os procedimentos cirúrgicos de cada área de formação, considerando seu grau de complexidade.

Estes procedimentos foram classificados em quatro níveis de complexidade crescente. O Quadro 2, de classificação por área e por complexidade, expressa, de forma inequívoca, a enorme diversidade de procedimentos realizados por um cancerologista cirúrgico em sua prática profissional. O domínio das capacidades necessárias à autonomia no exercício profissional com esse nível de expertise exige, na experiência dos membros do Grupo de Trabalho, inúmeros anos de formação continuada, em um processo que não se esgota com a conclusão da Residência Médica em Cancerologia Cirúrgica.

Frente à extensão e à complexidade da área, o Grupo de Trabalho entendeu ser necessária a definição de critérios mínimos para a certificação da competência profissional a ser alcançada na conclusão da Residência Médica em Cancerologia Cirúrgica. Para tanto, com base nos estudos epidemiológicos de prevalência e nas estimativas de incidência de câncer no Brasil, buscou definir, a partir do quadro de procedimentos por complexidade, aqueles que o egresso da Residência Médica deveria obrigatoriamente estar apto a executar com autonomia.

A este primeiro exercício de construção de critérios mínimos para a certificação dos egressos, seguiu-se um longo debate acerca das condições necessárias para o desenvolvimento e a operacionalização de programas de residência médica que garantam a formação de Cancerologistas Cirúrgicos com tal grau de autonomia na atuação profissional. O Grupo de Trabalho compreende que uma formação dessa natureza exige a exposição a numerosos cenários de prática para o desenvolvimento da competência profissional de forma a garantir a vivência da Atenção Oncológica em toda a sua abrangência, com o domínio de capacidades de complexidade crescente na perspectiva de uma formação de excelência voltada à integralidade do cuidado.

Um programa de residência assim orientado requer, para o desenvolvimento da competência esperada, um tempo mínimo de rodízio em cada área de formação da Cancerologia Cirúrgica. Desta forma, após novo debate, o Grupo de Trabalho entendeu que, para garantir tempos de rodízios adequados à uma formação de qualidade, seria necessário rever os critérios de prática profissional previamente delineados pelo Grupo. Assim, em uma nova oficina, definiram-se os procedimentos cirúrgicos que, classificados por níveis de desempenho (Quadro 3 ), seriam considerados obrigatórios (nível 1 de desempenho) ou apenas desejáveis (nível 2 de desempenho) em termos de prática com autonomia pelo residente ao término da formação.

O Quadro 3 mostra claramente que o "nível 1" de desempenho inclui procedimentos cirúrgicos de alta complexidade (graus 3 e 4 na classificação por complexidade). Sua inserção como critério de certificação justifica-se pela necessidade de o cancerologista cirúrgico ter expertise e autonomia para o manejo de condiçóes de elevada prevalência. 
Quadro 2. Procedimentos cirúrgicos, segundo o grau de complexidade

\begin{tabular}{|c|c|c|c|c|}
\hline & Grau 1 & Grau 2 & Grau 3 & Grau 4 \\
\hline 1. Mama & $\begin{array}{l}\text { Tumorectomias } \\
\text { (Exerese de } \\
\text { nódulos) } \\
\text { PAAF (Punção } \\
\text { aspirativa com } \\
\text { agulha fina) de } \\
\text { nódulos } \\
\text { Core-biopsia } \\
\text { (Biopsia por } \\
\text { fragmento com } \\
\text { agulha grossa) de } \\
\text { nódulos } \\
\text { Biopsia incisional } \\
\text { Biopsias de lesões } \\
\text { cutâneas da } \\
\text { mama } \\
\text { Drenagem e/ou } \\
\text { aspiração de } \\
\text { seromas }\end{array}$ & $\begin{array}{l}\text { Ressecção de Setor } \\
\text { Mamário } \\
\text { (Segmentectomia, } \\
\text { Quadrantectomias) } \\
\text { Mastectomia simples } \\
\text { Dutectomia } \\
\text { Centralectomias } \\
\text { Estudo de linfonodo } \\
\text { sentinela }\end{array}$ & $\begin{array}{l}\text { Ressecção de Setor } \\
\text { mamário com } \\
\text { linfadenectomia axilar } \\
\text { Centralectomia com } \\
\text { linfadenectomia axilar } \\
\text { Mastectomia radical } \\
\text { Mastectomia radical } \\
\text { modificada } \\
\text { Linfadenectomia axilar } \\
\text { Exerese de lesão } \\
\text { mamária por marcação } \\
\text { estereotáxica } \\
\text { Resgate em recidiva } \\
\text { loco-regionais de } \\
\text { pequeno porte em } \\
\text { câncer de mama }\end{array}$ & $\begin{array}{l}\text { Mastectomia com } \\
\text { reconstrução imediata } \\
\text { (skin-sparing ou outra } \\
\text { técnica) } \\
\text { Resgate em recidiva loco- } \\
\text { regionais de grande porte } \\
\text { em câncer de mama } \\
\text { Cirurgia radioguiada }\end{array}$ \\
\hline $\begin{array}{l}\text { 2. Cabeça e } \\
\text { Pescoço }\end{array}$ & $\begin{array}{l}\text { Tiróide/Paratiróide } \\
\text { /Glândulas } \\
\text { Salivares: } \\
\text { - Nasofibrolarin- } \\
\text { goscopia } \\
\text { - Biopsias para } \\
\text { diagnóstico } \\
\text { /tratamento } \\
\text { - Traqueostomias } \\
\text { Cavidade Oral } \\
\text { - Ressecção } \\
\text { simples de tumor } \\
\text { de boca } \\
\text { - Ressecção } \\
\text { simples de tumor } \\
\text { de lábio } \\
\text { - Glossectomia } \\
\text { parcial }\end{array}$ & $\begin{array}{l}\text { Tiróide/Paratiróide/ } \\
\text { Glândulas Salivares: } \\
\text { - Tireiodectomia sem } \\
\text { esvaziamento }\end{array}$ & $\begin{array}{l}\text { Tiróide/Paratiróide/ } \\
\text { Glândulas Salivares } \\
\text { - Tireiodectomia com } \\
\text { ou sem - esvaziamento } \\
\text { - Parotidectomia } \\
\text { - Paratireoidectomia } \\
\text { - Cirurgia de resgate } \\
\text { Cavidade Oral } \\
\text { - Reconstruções simples } \\
\text { - Esvaziamentos } \\
\text { cervicais } \\
\text { - Mandibulectomia } \\
\text { - Glossectomia } \\
\text { Laringe } \\
\text { - Esvaziamentos } \\
\text { cervicais } \\
\text { - Laringectomia total }\end{array}$ & $\begin{array}{l}\text { Cavidade Oral } \\
\text { - Pelviglossomandi- } \\
\text { bulectomia } \\
\text { Laringe } \\
\text { - Laringectomia parcial } \\
\text { - Cirurgias de resgate } \\
\text { (recidiva) }\end{array}$ \\
\hline 3.Tórax & $\begin{array}{l}\text { Parede torácica } \\
\text { - Drenagens } \\
\text { torácicas } \\
\text { - Pleurodese } \\
\text { - Biopsias }\end{array}$ & $\begin{array}{l}\text { Pulmão } \\
\text { - Pleuroscopia } \\
\text { Videotoracospia } \\
\text { diagnóstico) } \\
\text { - Broncoscopia } \\
\text { diagnóstica } \\
\text { Mediastino } \\
\text { - Mediastinoscopia } \\
\text { (diagnóstico) }\end{array}$ & $\begin{array}{l}\text { Pulmão } \\
\text { - Pneumectomia sem } \\
\text { linfadenectomia } \\
\text { - Segmentectomias } \\
\text { - Cunha/nodulectomia }\end{array}$ & $\begin{array}{l}\text { Pulmão } \\
\text { - Lobectomias radicais } \\
\text { - Pneumectomia com } \\
\text { linfadenectomia } \\
\text { - Traqueoplastia } \\
\text { Mediastino } \\
\text { - Ressecções tumores } \\
\text { mediastino } \\
\text { Parede torácica } \\
\text { - Toracectomia com ou sem } \\
\text { reconstrução }\end{array}$ \\
\hline
\end{tabular}




\begin{tabular}{|c|c|c|c|c|}
\hline & Grau 1 & Grau 2 & Grau 3 & Grau 4 \\
\hline 4. Digestório & $\begin{array}{l}\text { Estômago } \\
\text { - Cirurgias } \\
\text { Paliativas } \\
\text { (gastrostomia, } \\
\text { gastroenteroamas- } \\
\text { tomose } \\
\text { jejunostomia) }\end{array}$ & $\begin{array}{l}\text { Cólon/Reto/Ânus } \\
\text { - Ressecções } \\
\text { endoanais/Cirurgias } \\
\text { paliativas (cólon, reto, } \\
\text { ânus) } \\
\text { Retossigmoidoscopia } \\
\text { diagnóstica }\end{array}$ & $\begin{array}{l}\text { Estômago } \\
\text { - Gastrectomia parcial } \\
\text { com ou sem } \\
\text { linfadectomia } \\
\text { - Gastrectomia total } \\
\text { com ou sem } \\
\text { linfadectomia } \\
\text { - Recidivas } \\
\text { Fígado/Vias } \\
\text { Biliares/Pâncreas } \\
\text { - Pancreatectomia } \\
\text { - Derivações biliares } \\
\text { - Ressecção hepática } \\
\text { em cunha } \\
\text { Cólon/Reto/Ânus } \\
\text { - Colectomias } \\
\text { - Retossigmoidectomia } \\
\text { - Amputação } \\
\text { abdominoperineal } \\
\text { - Cirurgias profiláticas }\end{array}$ & $\begin{array}{l}\text { Esôfago } \\
\text { - Transposições } \\
\text { - Esofagectomia com ou } \\
\text { sem toracotomia } \\
\text { - Ressecções Multiorgânicas } \\
\text { Fígado/Vias } \\
\text { Biliares/Pâncreas } \\
\text { - Gastroduodeno- } \\
\text { pancreatectomia } \\
\text { - Hepatectomias } \\
\text { Cólon/Reto/Ânus } \\
\text { - Ressecções alargadas } \\
\text { - Exenterações pélvicas } \\
\text { - Procedimentos } \\
\text { laparoscópicos } \\
\text { Retroperitôneo } \\
\text { Ressecões de Tumores } \\
\text { retroperitôneais } \\
\text { Cirurgia cito-redutora e } \\
\text { quimioterapia } \\
\text { intraperitoneal hipertérmica }\end{array}$ \\
\hline $\begin{array}{l}\text { 5. Aparelho } \\
\text { Reprodutor } \\
\text { Feminino }\end{array}$ & $\begin{array}{l}\text { - Conização } \\
\text { - Cirurgia de alta } \\
\text { freqüência } \\
\text { - Vulvoscopia } \\
\text { - Colposcopia } \\
\text { - Curetagem } \\
\text { semiótica } \\
\text { - Histeroscopia } \\
\text { - Videolaparos- } \\
\text { copia diagnóstica } \\
\\
\text { - Linfadenectomias } \\
\text { inguinais } \\
\text { superficiais e } \\
\text { profundas }\end{array}$ & $\begin{array}{l}\text { Colo e Útero } \\
\text { - Histerectomias I e II } \\
\text { Vulva/Vagina } \\
\text { Vulvectomias parciais } \\
\text { Ovário/Trompa } \\
\text { - Salpingectomia } \\
\text { - Anexectomia } \\
\text { - Ooferectomia }\end{array}$ & $\begin{array}{l}\text { Colo e Útero } \\
\text { - Linfadenectomia } \\
\text { pélvica seletiva e } \\
\text { completa } \\
\text { - Linfadenectomia } \\
\text { para-aórtica } \\
\text { - Colpectomia } \\
\text { - Cirurgia via vaginal } \\
\text { Vulva/Vagina } \\
\text { - Colpectomias } \\
\text { Ovário } \\
\text { - Linfadenectomia } \\
\text { pélvica retroperitoneal } \\
\text { - Cirurgias } \\
\text { estadiamento } \\
\text { (linfadenectomias, } \\
\text { omemtectomias, } \\
\text { biopsias múltiplas, } \\
\text { histerectomia tipo I) }\end{array}$ & $\begin{array}{l}\text { Colo e Útero } \\
\text { Exenteração pélvica } \\
\text { Cirurgia de Wertheim } \\
\text { Meigs } \\
\text { Vulva/Vagina } \\
\text { - Vulvectomia radical } \\
\text { Ovário } \\
\text { - Citorredutoras/Resgate } \\
\text { - Procedimentos } \\
\text { videolaparoscópicos } \\
\text { terapêuticos }\end{array}$ \\
\hline
\end{tabular}




\begin{tabular}{|c|c|c|c|c|}
\hline Áreas & Grau 1 & Grau 2 & Grau 3 & Grau 4 \\
\hline $\begin{array}{l}\text { 6. Aparelho } \\
\text { Geniturinário } \\
\text { Masculino }\end{array}$ & $\begin{array}{l}\text { Próstata } \\
\text { - Orquiectomia } \\
\text { subcapsular } \\
\text { - Orquiectomia } \\
\text { total bilateral } \\
\text { - Citoscopia } \\
\text { diagnóstica }\end{array}$ & $\begin{array}{l}\text { Bexiga } \\
\text { - Ressecções } \\
\text { transuretrais } \\
\text { Testículo } \\
\text { - Orquiectomia radical } \\
\text { Pênis } \\
\text { - Amputações parciais } \\
\text { / totais }\end{array}$ & $\begin{array}{l}\text { Próstata } \\
\text { - Prostatectomia radical } \\
\text { Bexiga } \\
\text { - Cistectomia parcial } \\
\text { Pênis } \\
\text { - Emasculação } \\
\text { - Linfadenectomia } \\
\text { inguino-ilíaca } \\
\text { Rim } \\
\text { - Nefrectomias parciais } \\
\text { / radicais } \\
\text { - Suprarenalectomia }\end{array}$ & $\begin{array}{l}\text { Bexiga } \\
\text { - Cistoprostatectomia } \\
\text { radical } \\
\text { - Exenterações pélvicas } \\
\text { anteriores } \\
\text { - Derivações e } \\
\text { reconstruções urinárias } \\
\text { Testículos } \\
\text { - Linfadenectomias } \\
\text { retroperitoneais } \\
\text { Rim } \\
\text { - Videolaparoscopia } \\
\text { terapêutica }\end{array}$ \\
\hline $\begin{array}{l}\text { 7. Tecido } \\
\text { Ósseo e } \\
\text { Conectivo e } \\
\text { Pele }\end{array}$ & $\begin{array}{l}\text { Biopsias (partes } \\
\text { moles) } \\
\text { Melanomas } \\
\text { - Biopsias } \\
\text { Não-melanoma } \\
\text { - Ressecções locais } \\
\text { - Biopsias }\end{array}$ & $\begin{array}{l}\text { Melanomas } \\
\text { - Pesquisa do } \\
\text { linfonodo sentinela } \\
\text { Não-melanoma } \\
\text { - Ressecções } \\
\text { alargadas } \\
\text { - Reconstruções } \\
\text { (rotação de retalho e } \\
\text { enxerto) }\end{array}$ & $\begin{array}{l}\text { Amputações e } \\
\text { desarticulações } \\
\text { Ressecções } \\
\text { compartimentais em } \\
\text { extremidades } \\
\text { Melanomas } \\
\text { - Ressecções locais com } \\
\text { ou sem } \\
\text { linfadenectomias } \\
\text { topográficas } \\
\text { - Reconstruções com } \\
\text { retalhos miocutâneos } \\
\text { Não-melanoma } \\
\text { - Linfadenectomias } \\
\text { topográficas }\end{array}$ & $\begin{array}{l}\text { - Ressecções com } \\
\text { preservações de membros } \\
\text { em cintura } \\
\text { pélvica/escapular } \\
\text { (hemipelvectomias, } \\
\text { escapulectomias e Tickhoff- } \\
\text { Linberg) } \\
\text { - Ressecções multiviscerais } \\
\text { por tumores } \\
\text { retroperitoneais }\end{array}$ \\
\hline
\end{tabular}

*São considerados procedimentos desejáveis, mas não obrigatórios no desempenho final do residente 
Quadro 3. Procedimentos cirúrgicos, segundo o nível de desempenho

\begin{tabular}{|c|c|c|}
\hline Áreas & Nível 1 * & Nível 2 * \\
\hline 1. Mama & $\begin{array}{l}\text { Tumorectomias (Exerese de nódulos) } \\
\text { PAAF (Punção aspirativa com agulha fina) de nódulos } \\
\text { Core-Biopsia (Biopsia por fragmento com agulha } \\
\text { grossa) de nódulos } \\
\text { Biopsia incisional } \\
\text { Biopsias de lesões cutâneas da mama } \\
\text { Drenagem e/ou aspiração de seromas } \\
\text { Ressecção de Setor Mamário (Segmentectomia, } \\
\text { Quadrantectomias) } \\
\text { Mastectomia Simples } \\
\text { Dutectomia } \\
\text { Centralectomias } \\
\text { Estudo de linfonodo sentinela Ressecção de Setor } \\
\text { mamário com linfadenectomia axilar } \\
\text { Centralectomia com linfadenectomia axilar } \\
\text { Mastectomia radical } \\
\text { Mastectomia radical modificada } \\
\text { Linfadenectomia axilar } \\
\text { Exerese de lesão mamária por marcação estereotáxica } \\
\text { Resgate em recidiva loco-regionais de pequeno porte } \\
\text { em câncer de mama } \\
\text { Resgate em recidiva loco-regionais de grande porte } \\
\text { em câncer de mama } \\
\text { Cirurgia radioguiada }\end{array}$ & $\begin{array}{l}\text { Mastectomia com reconstrução } \\
\text { imediata (skin-sparing ou outra técnica) }\end{array}$ \\
\hline $\begin{array}{l}\text { 2. Cabeça e } \\
\text { Pescoço }\end{array}$ & $\begin{array}{l}\text { Tiróide/Paratiróide/Glândulas Salivares: } \\
\text { Nasofibrolaringoscopia } \\
\text { Biopsias para diagnóstico/tratamento } \\
\text { Traqueostomias } \\
\text { Tireoidectomia com ou sem esvaziamento } \\
\text { Glossectomia } \\
\text { Glossectomia parcial } \\
\text { Parotidectomia } \\
\text { Cavidade Oral } \\
\text { Ressecção simples de tumor de boca } \\
\text { Ressecção simples de tumor de lábio } \\
\text { Reconstruções simples } \\
\text { Esvaziamentos cervicais }\end{array}$ & $\begin{array}{l}\text { Cavidade Oral } \\
\text { - Mandibulectomia } \\
\text { - Pelviglossomandibulectomia } \\
\text { Laringe } \\
\text { - Laringectomia total } \\
\text { - Laringectomia parcial } \\
\text { Tiróide/Paratiróide/Glândulas Salivares } \\
\text { - Paratireoidectomia } \\
\text { - Cirurgias de resgate (recidiva) }\end{array}$ \\
\hline 3.Tórax & $\begin{array}{l}\text { Parede torácica } \\
\text { - Drenagens torácicas } \\
\text { - Pleurodese } \\
\text { - Biopsias } \\
\text { Pulmão } \\
\text { - Pleuroscopia / Videotoracoscopia (diagnóstico) } \\
\text { - Broncoscopia diagnóstica } \\
\text { - Segmentectomias } \\
\text { - Cunha/nodulectomia } \\
\text { - Lobectomias radicais } \\
\text { Mediastino } \\
\text { - Mediastinoscopia (diagnóstico) } \\
\text { Parede torácica } \\
\text { - Biopsias } \\
\text { - Toracectomia com ou sem reconstrução }\end{array}$ & $\begin{array}{l}\text { Pulmão } \\
\text { - Pneumectomia sem linfadenectomia } \\
\text { - Pneumectomia com linfadenectomia } \\
\text { - Traqueoplastia } \\
\text { Mediastino } \\
\text { - Ressecções tumores mediastino }\end{array}$ \\
\hline
\end{tabular}




\begin{tabular}{|c|c|c|}
\hline Áreas & Nível 1 * & Nível 2 * \\
\hline 4. Digestório & $\begin{array}{l}\text { Estômago } \\
\text { - Cirurgias Paliativas (gastrostomia, } \\
\text { gastroenteroanastomose, jejunostomia) } \\
\text { - Gastrectomia parcial com ou sem linfadectomia } \\
\text { - Gastrectomia total com ou sem linfadectomia } \\
\text { Cólon/Reto/Ânus } \\
\text { - Ressecções endoanais } \\
\text { - Cirurgias paliativas } \\
\text { - Colectomias } \\
\text { - Retossigmoidectomia } \\
\text { - Amputação abdominoperineal } \\
\text { - Cirurgias profiláticas/Ressecções alargadas } \\
\text { - Exenterações pélvicas } \\
\text { Fígado/Vias Biliares/Pâncreas } \\
\text { - Derivações biliares } \\
\text { - Resseçc̃o hepática em cunha } \\
\text { Retosigmoidoscopia diagnóstica }\end{array}$ & $\begin{array}{l}\text { Esôfago } \\
\text { - Transposições } \\
\text { - Esofagectomia com ou sem } \\
\text { toracotomia } \\
\text { - Ressecções Multiorgânicas } \\
\text { Estômago } \\
\text { - Recidivas } \\
\text { Fígado/Vias Biliares/Pâncreas } \\
\text { - Pancreatectomia } \\
\text { - Gastroduodenopancreatectomia } \\
\text { - Hepatectomias } \\
\text { Cólon/Reto/Ânus } \\
\text { - Procedimentos laparoscópicos } \\
\text { Retroperitôneo } \\
\text { - Ressecões de Tumores } \\
\text { retroperitoneais } \\
\text { - Cirurgia citorredutora e quimioterapia } \\
\text { intraperitoneal hipertérmica }\end{array}$ \\
\hline 5. Ginecologia & $\begin{array}{l}\text { - Conização } \\
\text { - Cirurgia de alta freqüência } \\
\text { - Vulvoscopia } \\
\text { - Colposcopia } \\
\text { - Curetagem semiótica } \\
\text { - Histeroscopia } \\
\text { - Videolaparoscopia diagnóstica } \\
\text { - Linfadenectomias inguinais superficiais e profundas } \\
\text { Colo e Útero } \\
\text { - Histerectomias I e II } \\
\text { - Linfadenectomia pélvica seletiva e completa } \\
\text { - Linfadenectomia para-aórtica } \\
\text { - Colpectomia } \\
\text { - Cirurgia via vaginal } \\
\text { - Exenteração pélvica } \\
\text { - Cirurgia de Wertheim Meigs } \\
\text { Ovário/Trompa } \\
\text { - Salpingectomia } \\
\text { - Anexectomia } \\
\text { - Ooferectomia } \\
\text { - Linfadenectomia pélvica retroperitoneal } \\
\text { - Cirurgias estadiamento (linfadenectomias, } \\
\text { omemtectomias, biopsias múltiplas, hiesterectomia } \\
\text { tipo I) } \\
\text { - Citorredutoras/Resgate } \\
\text { Vulva/Vagina } \\
\text { Vulvectomia parcial }\end{array}$ & $\begin{array}{l}\text { Vulva/Vagina } \\
\text { - Colpectomias } \\
\text { - Vulvectomia radical } \\
\text { Procedimentos videolaparoscópicos } \\
\text { terapêuticos }\end{array}$ \\
\hline
\end{tabular}




\begin{tabular}{|c|c|c|}
\hline Áreas & Nível $1 *$ & Nível 2 * \\
\hline 6. Urologia & $\begin{array}{l}\text { Próstata } \\
\text { - Orquiectomia subcapsular } \\
\text { - Orquiectomia total bilateral } \\
\text { - Citoscopia diagnóstica } \\
\text { - Prostatectomia radical } \\
\text { Bexiga } \\
\text { - Cistoprostatectomia radical } \\
\text { - Exenterações pélvicas anteriores } \\
\text { - Derivações e reconstruções urinárias } \\
\text { - Cistectomia parcial } \\
\text { Testículo } \\
\text { - Orquiectomia radical } \\
\text { - Linfadenectomias retroperitoneais } \\
\text { Pênis } \\
\text { - Linfadenectomia inguino-ilíaca }\end{array}$ & $\begin{array}{l}\text { Pênis } \\
\text { - Amputações parciais / totais } \\
\text { - Emasculação } \\
\text { Rim } \\
\text { - Nefrectomias parciais } \\
\text { - Supra-renalectomia } \\
\text { - Videolaparoscopia terapêutica (D) } \\
\text { Bexiga } \\
\text { - Ressecções transuretrais (D) }\end{array}$ \\
\hline $\begin{array}{l}\text { 7. Tecido Ósseo } \\
\text { e Conectivo e } \\
\text { Pele }\end{array}$ & $\begin{array}{l}\text { Biopsias (partes moles) } \\
\text { Amputações e desarticulações } \\
\text { Ressecções compartimentais em extremidades } \\
\text { Melanomas } \\
\text { - Biopsias } \\
\text { - Pesquisa do linfonodo sentinela } \\
\text { - Ressecções locais com ou sem linfadenectomias } \\
\text { topográficas } \\
\text { - Reconstruções com retalhos miocutâneos } \\
\text { Não-melanomas } \\
\text { - Ressecções locais } \\
\text { - Biopsias } \\
\text { - Ressecções alargadas } \\
\text { - Reconstruções (rotação de retalho e enxerto) } \\
\text { - Linfadenectomias topográficas }\end{array}$ & $\begin{array}{l}\text { Não-melanoma } \\
\text { - Ressecções com preservações de } \\
\text { membros em cintura pélvica/escapular } \\
\text { (hemipelvectomias, escapulectomias e } \\
\text { Tickhoff-Linberg) (D) } \\
\text { - Ressecções multiviscerais por tumores } \\
\text { retroperitoneais (D) }\end{array}$ \\
\hline
\end{tabular}

*(1) Nível 1 de Desempenho

Nível de exigência para certificação;

Orientado pela prevalência e grau de complexidade;

Condição de nivelamento do profissional (nacional).

*(2) Nível 2 de Desempenho

Nível desejável de exigência na certificação;

Orientada pela complexidade e pelas características institucionais e/ou regionais;

Condição de diferenciação do cirurgião oncológico;

Condiçãao da sofisticação tecnológica existente na instituição.

A seguir, após a definição dos níveis de desempenho esperados para cada área, o Grupo de Trabalho definiu, com base na reflexão sobre a frequiência de casos por patologia nos diferentes Serviços, a duração do rodízio por área da formação em Cancerologia Cirúrgica (Quadro 4). A opção do tempo de rodízio por área de formação e não por serviços/especialidades deveu-se ao fato de a organização dos serviços nas instituições formadoras não seguir um modelo único. Como exemplo, pode-se citar a incorporação por serviços de cirurgia abdominopélvica de especialidades que em outras instituiçôes organizam-se separadamente (ginecologia, urologia, cirurgia de abdome).

O Grupo de Trabalho pactuou, em seguida, os cenários e as atividades a serem desenvolvidas, ao longo de sua formação, pelos residentes de forma a ganhar as capacidades requeridas para alcançar os desempenhos previstos em cada uma das quatro áreas que compõem o perfil de competência do Cancerologista Cirúrgico (Apêndice D). O grupo definiu os conteúdos cognitivos 
mínimos para cada "área de competência" (Apêndice E) a serem explorados no conjunto de atividades teóricopráticas desenvolvidas ao longo da formação.

Adicionalmente, à diversidade de intervenções para as quais deve ganhar expertise, característica do exercício profissional do Cancerologista Cirúrgico, associa-se a abordagem multidisciplinar requerida para a excelência do manejo clínico-cirúrgico do câncer em todas as etapas de sua evolução. A formação do Cancerologista Cirúrgico requer, por isso, além da capacidade para a realização de procedimentos cirúrgicos, o desenvolvimento de capacidades para a eleição das alternativas mais adequadas de tratamento quimioradioterápico e cirúrgico ao longo da enfermidade. Nesse sentido, o Grupo de Trabalho propõe que os programas de Residência Médica em Cancerologia Cirúrgica tenham inseridos, nos múltiplos cenários da formação na área, a Radioterapia, a Oncologia Clínica, a Anatomia Patológica e os Cuidados Paliativos como eixos disciplinares transversais durante toda a formação. Os tempos de formação nessas áreas incorporam-se, assim, às atividades desenvolvidas nos períodos de rodízio nas áreas apresentadas no Quadro 4.

Quadro 4. Duração do rodízio por área da formação em Cancerologia Cirúrgica

\begin{tabular}{|l|c|c|}
\hline \multicolumn{1}{|c|}{ Áreas de Rodízio } & Meses & $\begin{array}{c}\text { Carga } \\
\text { Horária }\end{array}$ \\
\hline Férias & 3 & 720 horas \\
\hline Tórax & 3 & 720 horas \\
\hline Urologia & 4 & 960 horas \\
\hline $\begin{array}{l}\text { Pele e Tecido Ósseo e } \\
\text { Conectivo Oncológico }\end{array}$ & 4 & 960 horas \\
\hline Ginecologia & 4 & 960 horas \\
\hline Mastologia & 4 & 960 horas \\
\hline Cabeça e Pescoço & 4 & 960 horas \\
\hline Abdome & 10 & 2400 horas \\
\hline Total & 36 & 8640 horas \\
\hline
\end{tabular}

Pode-se observar, na análise do Quadro 4, que um programa de Residência Médica em Cancerologia Cirúrgica construído desta forma tem duração mínima de três anos. Tal observação vem ao encontro dos modelos de formação adotados em outros países com tradição em Residência Médica nessa área e que, há longa data, orientam seus programas por competência. Adicionalmente, a repercussão negativa, junto aos residentes, da redução na duração dos programas de Residência Médica em Cancerologia Cirúrgica se refletiu em um fenômeno observado em $80 \%$ das instituições formadoras: os residentes, já de posse de seus certificados legais de conclusão, solicitaram autorização para a permanência por mais um ano nos serviços, em alguns casos sem direito à bolsa, com vistas a complementar a sua formação. A força de tal solicitação torna explícito aquilo que a experiência dos formadores nesta área já apontara: não é possível formar com qualidade um Cancerologista Cirúrgico em apenas dois anos.

\section{CONCLUSÃO}

O presente documento-síntese é o fruto de um árduo processo de construção coletiva - inúmeras reuniōes, momentos de impasse, uma enorme disposição para o diálogo e o consenso. Tamanho esforço se justifica pela relevância do controle do câncer no país, problema de saúde pública, área hoje prioritária para o Ministério da Saúde.

A dedicação de todos os envolvidos nesse processo, no qual se destaca a participação e liderança das duas "instituiçôes-mater" da formação em Cancerologia no país - A.C. Camargo e INCA - expressa o compromisso e a preocupação com a qualidade da formação para a Atenção Oncológica no Brasil. Nesse movimento iniciado pelo Conselho Consultivo do INCA (CONSINCA), as instituiçôes formadoras inseriramse de forma decisiva, ampliando a reflexão e as possibilidades na construção de programas de Residência Médica voltados ao enfrentamento do problema do câncer no país.

A elaboração desse documento representa o término de uma etapa e anuncia o próximo desafio: implementar, na prática, as mudanças tão necessárias à melhoria da qualidade na formação do Cancerologista Cirúrgico.

A situação da formação do cancerologista cirúrgico é, por um lado, única e singular; mas, se analisada no bojo da formação em nível de residência médica para especialidades com pré-requisito, reflete o padrão da desigualdade de distribuição de programas no país, ainda fortemente concentrados na região sudeste, como mostra a Figura 1. A força dos determinantes dessa situação de desigualdade se faz sentir quando é analisada a distribuição de postos de trabalho de especialistas em oncologia no país, mostrando claramente uma tendência de concentração crescente à medida que se avança do norte para o sul e do interior para o litoral do país, tal como revela a Figura 2. O cotejamento dessa tendência de distribuição com os dados epidemiológicos atesta $o$ desafio a ser enfrentado no campo das políticas públicas orientadas para a formação de recursos humanos em saúde. 


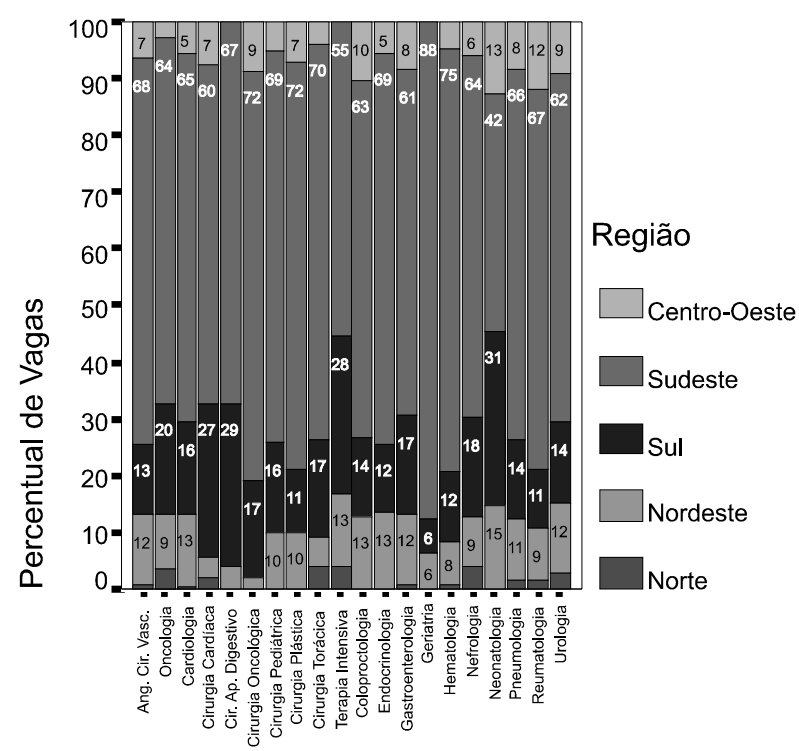

Figura 1. Residência médica em especialidades com pré-requisito $-\%$ de vagas credenciadas por região e programa

Fonte: Estudo para a identificação de necessidades de profissionais e especialistas na área da saúde. Componente: Residência Médica. Faculdade de Medicina da Universidade de São Paulo. In: Ceccim, Ricardo Burg e Feuerwerker, Laura (Org). Estudo sobre a necessidade de profissionais e de especialistas em saúde: análise em multicentros de pesquisa. Brasília: Conselho Nacional de Saúde; 2005. [5 arquivos em power point (acervo dos autores)].
Aceitar esse desafio implica ampliar ainda mais as parcerias entre as instituiçōes formadoras e assegurar o envolvimento de outras esferas da área da saúde e da educação, sem as quais a legitimidade do processo não ganha a força do valor legal e de diretriz de política pública.

Nesse sentido, o reconhecimento pela Comissão Nacional de Residência Médica (CNRM/MEC), instância reguladora da Residência Médica no país, tornou-se indispensável à continuidade deste processo de reorganização da formação para a Atenção Oncológica no Brasil. O projeto foi apresentado em plenária da referida Comissão em junho de 2006, aprovado e publicado em Diário Oficial da Uniãos.

\section{AGRADECIMENTOS}

A autora/relatora agradece a inestimável colaboração da Dra Valéria Vernashi Lima, consultora do projeto e facilitadora das oficinas 1 e 2 .
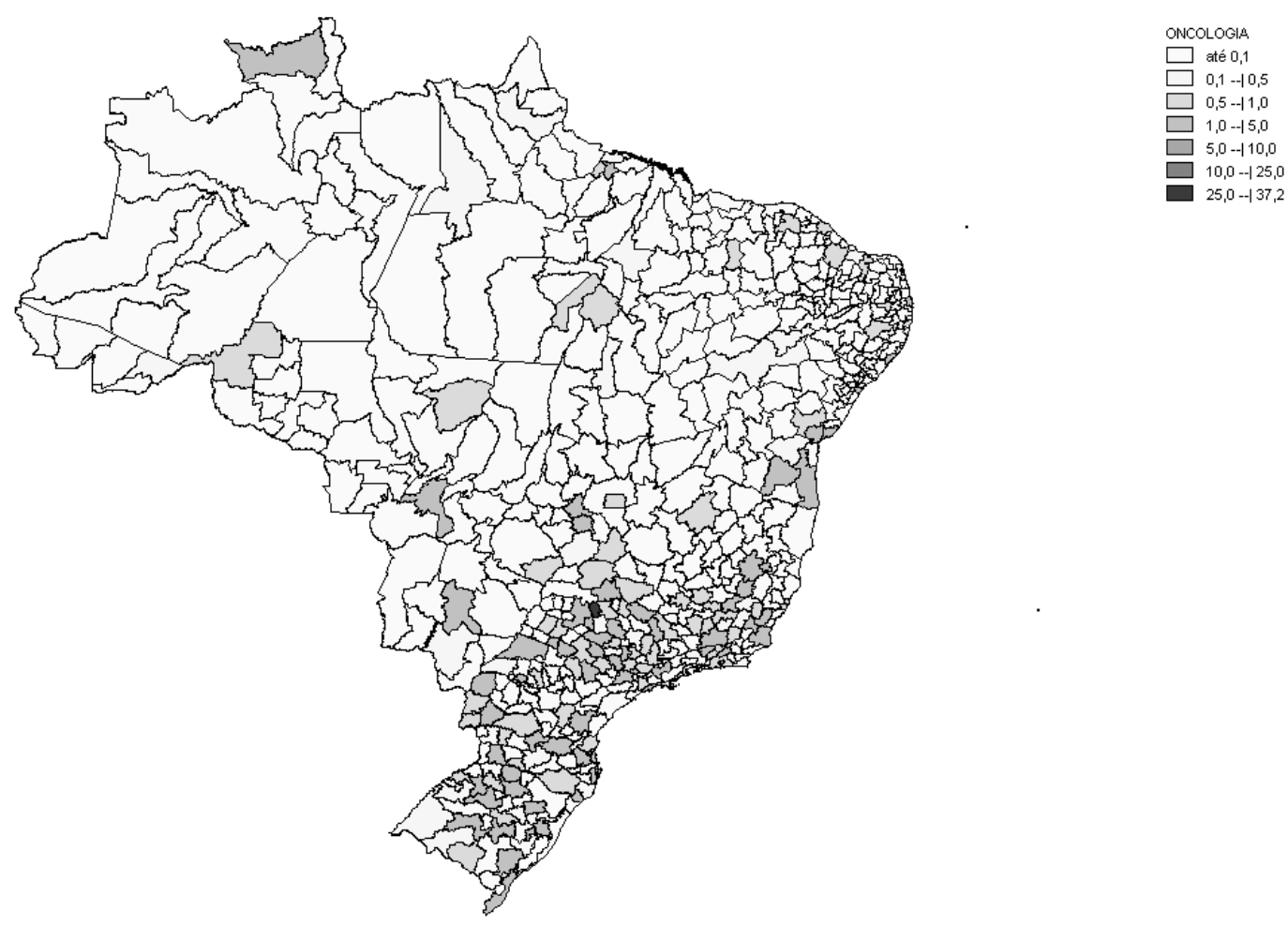

Figura 2. Coeficiente de Vínculos Médicos na Área de Oncologia por 100.000 habitantes

Fonte: Estudo para a identificação de necessidades de profissionais e especialidades na área da saúde. Componente: distribuição espacial dos vínculos empregatícios das especialidades médicas. UFRGS. In: Ceccim, Ricardo Burg e Feuerwerker, Laura (Org). Estudo sobre a necessidade de profissionais e de especialistas em saúde: análise em multicentros de pesquisa. Brasília: Conselho Nacional de Saúde; 2005. [5 arquivos em power point (acervo dos autores)] 


\section{REFERÊNCIAS}

1. Lima VV. Competência: distintas abordagens e implicaçôes na formação de profissionais de saúde. Interface. 2005;9(17):369-79.

2. Ribeiro ECO, LimaVV.Termo de Referência "Projeto: ENSP em Movimento". Documento Técnico. Escola de Governo da Escola Nacional de Saúde Pública: FIOCRUZ; 2004.

3. Hernandez D. Acreditação e certificação profissional. Palestra proferida em 6 de dezembro de 2002 no Núcleo de Tecnologia Educacional para a Saúde. Rio de Janeiro: Universidade Federal do Rio de Janeiro. mimeo.

4. Instituto Nacional de Câncer (INCA/MS). Estimativas 2006: Incidência de Câncer no Brasil. Rio de Janeiro: INCA; 2005.

5. Brasil. D.O.U. no 208, de 30/10/06, seção 1, pág. 72 por ter saído com omissão do anexo no D.O.U. no 177, de 14/ 9/06, seção 1, pág. 17. 
Apêndice A. Instituições Indicantes e Cirurgiões Oncológicos Indicados para a Oficina 2

\begin{tabular}{|c|c|c|c|c|}
\hline INSTITUIÇÃO & INDICANTE & CIRURGIÃO Indicado & SUPLENTE 1 & SUPLENTE 2 \\
\hline $\begin{array}{l}\text { ABIFCC } \\
(\text { TITULAR 1) }\end{array}$ & $\begin{array}{l}\text { Dr. Ademar Lopes } \\
\text { (Indicado por Dr. Ricardo } \\
\text { Renzo Brentani) }\end{array}$ & Dr. Sabas Carlos Vieira & $\begin{array}{l}\text { Dr. Cassio Cortez } \\
\text { Santos }\end{array}$ & $\begin{array}{l}\text { Dr. Marcos Nolasco } \\
\text { Hora das Neves }\end{array}$ \\
\hline $\begin{array}{l}\text { ABIFCC } \\
(\text { TITULAR 2) }\end{array}$ & $\begin{array}{l}\text { Dr. Ademar Lopes } \\
\text { (Indicado por Dr. Ricardo } \\
\text { Renzo Brentani) }\end{array}$ & $\begin{array}{l}\text { Dr. Marcio Ribeiro } \\
\text { Studart da Fonseca }\end{array}$ & $\begin{array}{l}\text { Dr. Paulo Henrique } \\
\text { Zanvettor }\end{array}$ & $\begin{array}{l}\text { Luis Fernando Pinto } \\
\text { Johnson }\end{array}$ \\
\hline ABRAHUE & $\begin{array}{l}\text { Dr. Amâncio Paulino de } \\
\text { Carvalho }\end{array}$ & & & \\
\hline $\begin{array}{l}\text { ABEM } \\
\text { (Associação de } \\
\text { Educação } \\
\text { Médica) }\end{array}$ & Dr. Milton Arruda Martins & & & \\
\hline $\mathrm{AMB}$ & Dr. Eleuses Vieira de Paiva & & & \\
\hline CEREMERJ & $\begin{array}{l}\text { Dr. José Carlos de Souza } \\
\text { Lima - }\end{array}$ & & & \\
\hline $\begin{array}{l}\text { Conselho Federal } \\
\text { de Medicina - } \\
\text { CFM }\end{array}$ & Dr. Edson de Andrade & & & \\
\hline $\begin{array}{l}\text { CMB - } \\
\text { Misericórdias do } \\
\text { Brasil }\end{array}$ & $\begin{array}{l}\text { Dr. Luiz Antonio Negrão } \\
\text { Dias }\end{array}$ & $\begin{array}{l}\text { Dr. Sergio B.B. } \\
\text { Hatshbach }\end{array}$ & $\begin{array}{l}\text { Dr. Massakazu } \\
\text { Kato }\end{array}$ & $\begin{array}{l}\text { Dr. Giovanni Targa } \\
\text { ou Dr. Valdecir de } \\
\text { Oliveira }\end{array}$ \\
\hline CNRM & Dr. Antonio Carlos Lopes & & & \\
\hline $\begin{array}{l}\text { CONASEMS } \\
\text { (CONSINCA) }\end{array}$ & $\begin{array}{l}\text { Dr. Luiz Odorico Monteiro } \\
\text { de Andrade }\end{array}$ & & & \\
\hline $\begin{array}{l}\text { CONASS } \\
\text { (CONSINCA) }\end{array}$ & Dr. Gilson Cantarino & & & \\
\hline $\begin{array}{l}\text { Fundação } \\
\text { Antonio Prudente } \\
\text { - Hospital A. C. } \\
\text { Camargo }\end{array}$ & Dr. Samuel Aguiar Junior & $\begin{array}{l}\text { Dr. Fábio de Oliveira } \\
\text { Ferreira }\end{array}$ & Dr. Ademar Lopes & $\begin{array}{l}\text { Dr. Benedito Mauro } \\
\text { Rossi }\end{array}$ \\
\hline $\begin{array}{l}\text { Hospital Araújo } \\
\text { Jorge - } \\
\text { Associação CC } \\
\text { GOIÁS }\end{array}$ & $\begin{array}{l}\text { Dr. Adriano Peclat de } \\
\text { Paula }\end{array}$ & $\begin{array}{l}\text { Dr. Adriano Augusto } \\
\text { Peclat de Paula }\end{array}$ & $\begin{array}{l}\text { José Carlos de } \\
\text { Oliveira }\end{array}$ & \\
\hline $\begin{array}{l}\text { Hospital de } \\
\text { Câncer.de } \\
\text { Manaus - } \\
\text { FCECON }\end{array}$ & $\begin{array}{l}\text { Dr. Jose A.Ferreira de } \\
\text { Assunção }\end{array}$ & $\begin{array}{l}\text { Dr. Leônidas Alves da } \\
\text { Silva }\end{array}$ & $\begin{array}{l}\text { Sidney Raimundo } \\
\text { Chalub }\end{array}$ & \\
\hline $\begin{array}{l}\text { Hospital de } \\
\text { Câncer de } \\
\text { Pernambuco }\end{array}$ & Dr. Felipe Lorenzatto & $\begin{array}{l}\text { Dr. Artur Licio Rocha } \\
\text { Bezerra }\end{array}$ & $\begin{array}{l}\text { Leonardo de } \\
\text { Siqueira B. } \\
\text { Arcoverde }\end{array}$ & $\begin{array}{l}\text { Antonio Marcelo } \\
\text { G.de Souza }\end{array}$ \\
\hline INCA & Dr. Walter Roriz & $\begin{array}{l}\text { Dr. Mauro Monteiro } \\
\text { Correia }\end{array}$ & $\begin{array}{l}\text { Dr. Eliezer } \\
\text { Leiderman }\end{array}$ & $\begin{array}{l}\text { Dr. Rafael Oliveira } \\
\text { Albagli }\end{array}$ \\
\hline $\begin{array}{l}\text { Irmandade da } \\
\text { Santa Casa de } \\
\text { Misericórdia de } \\
\text { Porto Alegre }\end{array}$ & Dr. Jaques Bacaltchuck & $\begin{array}{l}\text { Dr. Antonio Nocchi } \\
\text { Kalil }\end{array}$ & $\begin{array}{l}\text { Dr. José Pio } \\
\text { Furtado }\end{array}$ & \\
\hline $\begin{array}{l}\text { Liga Paranaense } \\
\text { de Combate ao } \\
\text { Câncer }\end{array}$ & Flavio Tomasich & Claudiane L. M. Bozko & $\begin{array}{l}\text { Paulo Fernando } \\
\text { Bozko }\end{array}$ & Flavio Daniel \\
\hline $\begin{array}{l}\text { MS - Insumos } \\
\text { Estratégicos }\end{array}$ & $\begin{array}{l}\text { Dr. Dirceu Brás Aparecido } \\
\text { Barbano }\end{array}$ & $\begin{array}{l}\text { Dr. Antonio Gonçalves } \\
\text { de Oliveira Filho }\end{array}$ & $\begin{array}{l}\text { Simone dos Santos } \\
\text { Aguiar }\end{array}$ & \\
\hline
\end{tabular}




\begin{tabular}{|c|c|c|c|c|}
\hline INSTITUIÇÃO & INDICANTE & CIRURGIÃO Indicado & SUPLENTE 1 & SUPLENTE 2 \\
\hline $\begin{array}{l}\text { MS - Redes } \\
\text { Assistenciais }\end{array}$ & $\begin{array}{l}\text { Dr. Carlos Armando L.do } \\
\text { Nascimento }\end{array}$ & & & \\
\hline SEGETS / DEGES & Dr. Ricardo Ceccim & & & \\
\hline $\begin{array}{l}\text { SBC } \\
\text { (CONSINCA) }\end{array}$ & Dra. Lair Ribeiro & Dr. André Perdicaris & Dr. Robson Moura & Dr. Ricardo Antunes \\
\hline $\begin{array}{l}\text { SBCO } \\
\text { (CONSINCA) }\end{array}$ & Dr. Odilon de Souza Filho & $\begin{array}{l}\text { Dr. Luiz Antonio } \\
\text { Negrão Dias }\end{array}$ & $\begin{array}{l}\text { Alexandre Ferreira } \\
\text { Oliveira }\end{array}$ & \\
\hline $\begin{array}{l}\text { SBOC } \\
\text { (CONSINCA) }\end{array}$ & $\begin{array}{l}\text { Dr. Roberto de Almeida } \\
\text { Gil }\end{array}$ & $\begin{array}{l}\text { Dr. José Pio Rodrigues } \\
\text { Furtado }\end{array}$ & Dr. Raul Pruinelli & \\
\hline $\begin{array}{l}\text { Hospital Felício } \\
\text { Rocho (MG) }\end{array}$ & Dr. Sinval Lins e Silva & & & \\
\hline $\begin{array}{l}\text { Hospital Celso } \\
\text { Ramos (SC) }\end{array}$ & $\begin{array}{l}\text { Dr. Carlos Alberto } \\
\text { LACOMBE }\end{array}$ & $\begin{array}{l}\text { Dr. Danton Spohr } \\
\text { Correa }\end{array}$ & & \\
\hline $\begin{array}{l}\text { Hospital } \\
\text { Conceição (RS) }\end{array}$ & $\begin{array}{l}\text { Dr. João Constantino } \\
\text { Motta }\end{array}$ & Dr. Raul Pruinelli & $\begin{array}{l}\text { Herbert Jorges } \\
\text { Scmitz }\end{array}$ & $\begin{array}{l}\text { Hamilton Cardoso } \\
\text { Hilgert }\end{array}$ \\
\hline $\begin{array}{l}\text { Hospital Ofir } \\
\text { Loyola }\end{array}$ & Dr. Nilo Alves Almeida & $\begin{array}{l}\text { Dr. Marcelo Bandeira } \\
\text { Coelho Dias }\end{array}$ & $\begin{array}{l}\text { Vitor Moutinho da } \\
\text { Conceição }\end{array}$ & $\begin{array}{l}\text { Antenor Madeira } \\
\text { Neto }\end{array}$ \\
\hline $\begin{array}{l}\text { Instituto do } \\
\text { Câncer do Ceará }\end{array}$ & $\begin{array}{l}\text { Dr. Sergio Ferreira } \\
\text { Juaçaba }\end{array}$ & $\begin{array}{l}\text { Dr. Fábio Machado } \\
\text { Landim }\end{array}$ & $\begin{array}{l}\text { Dr. Marcelo Leite } \\
\text { V.Costa }\end{array}$ & $\begin{array}{l}\text { Dr. Carlos Felipe S. } \\
\text { Beserra }\end{array}$ \\
\hline $\begin{array}{l}\text { Hospital Sírio e } \\
\text { Libanês (SP) }\end{array}$ & $\begin{array}{l}\text { Dr. Mauricio Ceschin ou } \\
\text { Dr. André Alexandre } \\
\text { Osmo }\end{array}$ & Dr. Raul Cutait & $\begin{array}{l}\text { Dr. Riad Naim } \\
\text { Younes }\end{array}$ & \\
\hline $\begin{array}{l}\text { Hospital Amaral } \\
\text { de Carvalho } \\
\text { (Jaú) }\end{array}$ & $\begin{array}{l}\text { Dr. Antonio Luis Cesarino } \\
\text { de Moraes Navarro }\end{array}$ & $\begin{array}{l}\text { Dr. José Getúlio } \\
\text { Martins Segalla }\end{array}$ & $\begin{array}{l}\text { Dr. José Roberto } \\
\text { Fígaro Caldeira }\end{array}$ & $\begin{array}{l}\text { Dr. José Valfredo } \\
\text { Budim }\end{array}$ \\
\hline $\begin{array}{l}\text { Sociedade de } \\
\text { Radioterapia }\end{array}$ & João Luiz Fernandes & Dr. Francisco Belfort & Dr. Rafael Pozik & Dr. Fabio Ferreira \\
\hline ANMR & André Kiymitsu Sediyama & $\begin{array}{l}\text { Dr Marcelo Sá de } \\
\text { Araújo }\end{array}$ & & \\
\hline $\begin{array}{l}\text { Sociedade de } \\
\text { Enfermagem } \\
\text { Oncológica }\end{array}$ & Ângela Coe & $\begin{array}{l}\text { Dr. José Edson } \\
\text { Myranda }\end{array}$ & & \\
\hline $\begin{array}{l}\text { Sociedade de } \\
\text { Anestesiologia }\end{array}$ & Dr. Henri Braunstein & & & \\
\hline $\begin{array}{l}\text { Associação } \\
\text { Brasileira de } \\
\text { Registros de } \\
\text { Câncer }\end{array}$ & $\begin{array}{l}\text { Dr. Elmando Sampaio } \\
\text { Silva / Hospital Aristides } \\
\text { Maltes }\end{array}$ & $\begin{array}{l}\text { Robson Fontes de } \\
\text { Moura }\end{array}$ & & \\
\hline ABIFCC & $\begin{array}{l}\text { Dr. Ricardo José Curioso } \\
\text { da Silva }\end{array}$ & Dr. Luciano Luiz & $\begin{array}{l}\text { Dr. Antonio Fortes } \\
\text { de Pádua } F^{\circ}\end{array}$ & $\begin{array}{l}\text { Dr. Ivan Marcelo } \\
\text { Agra }\end{array}$ \\
\hline ABIFCC & $\begin{array}{l}\text { Dr. Ricardo José Curioso } \\
\text { da Silva }\end{array}$ & $\begin{array}{l}\text { Dr. Paulo Henrique } \\
\text { Zanvettor }\end{array}$ & $\begin{array}{l}\text { Dr. Ademar } \\
\text { Benévolo }\end{array}$ & Dr. Helder (MA) \\
\hline ABIFCC & Dr. Ademar Lopes & Dr. Sabas Carlos Vieira & $\begin{array}{l}\text { Dr. Cassio Cortez } \\
\text { Santos }\end{array}$ & $\begin{array}{l}\text { Dr. Marcos Nolasco } \\
\text { Hora das Neves }\end{array}$ \\
\hline ABIFCC & Dr. Ademar Lopes & $\begin{array}{l}\text { Dr. Marcio Ribeiro } \\
\text { Studart da Fonseca }\end{array}$ & $\begin{array}{l}\text { Dr. Paulo Henrique } \\
\text { Zanvettor }\end{array}$ & $\begin{array}{l}\text { Luis Fernando Pinto } \\
\text { Johnson }\end{array}$ \\
\hline
\end{tabular}


Área de Competência 1: Clínico-cirúrgica

\begin{tabular}{|c|c|}
\hline Ações & Desempenhos (atividades qualificadas) \\
\hline \multirow[t]{6}{*}{$\begin{array}{l}1 \text { - Realiza } \\
\text { diagnóstico }\end{array}$} & $\begin{array}{l}\text { 1. Realiza anamnese e exame físico minuciosos, direcionados à identificação de doença } \\
\text { tumoral, comorbidades e fatores de risco (individuais e familiares), estabelecendo relação } \\
\text { interpessoal empática na abordagem clínico-cirúrgica, aberta à identificação das } \\
\text { necessidades singulares do paciente em cada momento da evolução de sua enfermidade; }\end{array}$ \\
\hline & $\begin{array}{l}\text { 2. Informa de modo claro e seguro ao paciente quanto às etapas necessárias para o } \\
\text { diagnóstico/estadiamento da doença, com sensibilidade e respeito para seus valores, } \\
\text { necessidades e crenças e de forma a garantir a compreensão do que julga que o paciente } \\
\text { deve saber e o que precisa informar-lhe para que a melhor decisão seja tomada; }\end{array}$ \\
\hline & $\begin{array}{l}\text { 3. Obtém o consentimento livre e esclarecido para procedimentos diagnósticos garantindo, } \\
\text { por meio de comunicação adequada, o esclarecimento aos familiares/cuidadores e/ou } \\
\text { paciente quanto aos riscos/benefícios das diferentes etapas diagnósticas em seu caso; }\end{array}$ \\
\hline & $\begin{array}{l}\text { 4. Indica os procedimentos diagnósticos necessários a cada etapa da investigação, } \\
\text { assegurando o registro de informações objetivas e relevantes para o caso e o diálogo com os } \\
\text { profissionais da equipe multiprofissional envolvida para a obtenção da melhor interpretação } \\
\text { que cada recurso oferece. Busca a melhor relação custo/efetividade dos recursos } \\
\text { diagnósticos disponíveis e adequados a cada caso. Considera, para tanto, o contexto } \\
\text { socioeconômico, as particularidades físicas, emocionais e socioculturais de cada doente, bem } \\
\text { como a avaliação da qualidade de exames e procedimentos ci rúrgicos realizados } \\
\text { previamente; }\end{array}$ \\
\hline & $\begin{array}{l}\text { 5. Estabelece correlação clínico-histopatológica, em estreita colaboração com o } \\
\text { anatomopatologista e com a participação de outros profissionais da equipe multidisciplinar, } \\
\text { nas fases pré, intra e pós-operatórias, com vistas ao diagnóstico e estadiamento mais preciso } \\
\text { para subsidiar as tomadas de decisão necessárias ao planejamento terapêutico; }\end{array}$ \\
\hline & $\begin{array}{l}\text { 6. Realiza, no curso da progressão da enfermidade, diagnósticos quanto à doença primária, } \\
\text { comorbidades, síndromes paraneoplásicas, complicações e emergências (relativas à } \\
\text { evolução da doença e/ou ao tratamento), recidivas e surgimento de outros tumores com base } \\
\text { nos diagnósticos diferenciais para a doença tumoral, na interpretação dos dados obtidos na } \\
\text { anamnese, no exame físico, exames complementares e histopatológicos. }\end{array}$ \\
\hline \multirow[t]{4}{*}{$\begin{array}{l}2 \text { - Estabelece plano } \\
\text { de cuidado }\end{array}$} & $\begin{array}{l}\text { 1. Participa do planejamento das intervenções terapêuticas em todo o espectro do cuidado } \\
\text { clínico-cirúrgico, desde a neo-adjuvância até a paliação, em trabalho multiprofissional e } \\
\text { multidisciplinar, na perspectiva da melhor qualidade de sobrevida, visando, quando possível, } \\
\text { à cura da doença, considerando, de forma individualizada, os contextos social, econômico e } \\
\text { cultural do paciente e racionalizando e otimizando os recursos disponíveis em cada caso; }\end{array}$ \\
\hline & $\begin{array}{l}\text { 2. Inclui as necessidades identificadas pela escuta atenta de pacientes/familiares/cuidadores } \\
\text { como elemento relevante nas tomadas de decisão ao longo da evolução da enfermidade, } \\
\text { considerando-as frente aos riscos/benefícios das diferentes alternativas terapêuticas (clínicas } \\
\text { e cirúrgicas), garantindo com isso a maior autonomia possível nas decisões tomadas; }\end{array}$ \\
\hline & $\begin{array}{l}\text { 3. Comunica de forma clara e objetiva, ao longo da enfermidade, aos familiares/cuidadores } \\
\text { e/ou paciente quanto aos riscos envolvidos nos procedimentos terapêuticos planejados; }\end{array}$ \\
\hline & $\begin{array}{l}\text { 4.Avalia, em cada caso, em estreita colaboração com o oncologista clínico e outros membros } \\
\text { da equipe, a melhor estratégia em termos de momento para a abordagem cirúrgica, porte e } \\
\text { duração, tendo em vista a preparação clínico-psicológica e a relação custo/benefício para o } \\
\text { paciente, incluindo juízo sobre o risco de morte imediato, chance de cura/recorrência da } \\
\text { doença, grau de mutilação e qualidade de vida. Com base nessa avaliação, disponibiliza } \\
\text { tempo necessário e suficiente para que o ato cirúrgico transcorra com tranqüilidade; }\end{array}$ \\
\hline
\end{tabular}




\begin{tabular}{|c|c|}
\hline Ações & Desempenhos (atividades qualificadas) \\
\hline \multirow[t]{2}{*}{$\begin{array}{l}2 \text { - Estabelece plano } \\
\text { de cuidado (cont.) }\end{array}$} & $\begin{array}{l}\text { 5. Orienta a tomada de decisões frente à evolução desfavorável da doença pela ponderação } \\
\text { entre a tenacidade da busca da melhor alternativa de intervenção e o reconhecimento, com } \\
\text { objetividade, dos limites terapêuticos, responsabilizando-se pelo paciente e assegurando o } \\
\text { investimento e o acolhimento de suas necessidades no curso da enfermidade e diante da } \\
\text { perspectiva da morte; identifica a condição de paciente no limite das possibilidades } \\
\text { terapêuticas, informando à família e à equipe responsável pelo cuidado ao doente a fim de } \\
\text { evitar distanásia; }\end{array}$ \\
\hline & $\begin{array}{l}\text { 6. Mobiliza os recursos da equipe multiprofissional para atender as necessidades efetivas de } \\
\text { paliação nas dimensões técnica, psicológica e social e para promover a reinserção familiar e } \\
\text { social do paciente em cada etapa do tratamento cirúrgico, permanecendo atento às } \\
\text { necessidades individuais e coletivas do paciente e seus familiares. }\end{array}$ \\
\hline \multirow[t]{3}{*}{$\begin{array}{l}3 \text { - Realiza } \\
\text { terapêutica cirúrgica }\end{array}$} & $\begin{array}{l}\text { 1. No ato cirúrgico, avalia de forma sistemática e hábil a extensão loco-regional da doença, } \\
\text { atentando para texturas, tonalidades e consistência dos tecidos por visualização e palpação } \\
\text { minuciosas, interagindo com o anatomopatologista de forma a melhor orientar a tomada de } \\
\text { decisões quanto ao diagnóstico histopatológico mais acurado e à ressecção necessária em } \\
\text { cada caso; compartilha com a equipe multidisciplinar as estratégias que eventualmente } \\
\text { sejam necessárias no per e pós-operatórios imediato; }\end{array}$ \\
\hline & $\begin{array}{l}\text { 2. Realiza ressecção tumoral, preservando ao máximo e segundo a melhor técnica a } \\
\text { integridade dos tecidos, com vistas a evitar a contaminação do campo cirúrgico por células } \\
\text { tumorais e a obter o melhor resultado em termos de tratamento cirúrgico; avalia e demarca } \\
\text { limites anatômicos com vistas a um possível tratamento radioterápico adjuvante; }\end{array}$ \\
\hline & $\begin{array}{l}\text { 3. Identifica e intervém nas complicações ocorridas durante ou em conseqüência ao ato } \\
\text { cirúrgico, nos diversos sistemas orgânicos, mobilizando os recursos necessários para } \\
\text { minimizar o estresse cirúrgico da equipe surgido frente aos imprevistos e às dificuldades } \\
\text { implícitas ao ato cirúrgico, direcionando o trabalho da equipe cirúrgica e em cooperação } \\
\text { multidisciplinar, para obtenção dos melhores resulta dos quanto à ressecabilidade possível. }\end{array}$ \\
\hline
\end{tabular}

Área de Competência 2: Gestão

\begin{tabular}{|c|c|}
\hline Ações & Desempenhos (atividades qualificadas) \\
\hline $\begin{array}{l}1 \text { - Identifica } \\
\text { necessidades da } \\
\text { organização do } \\
\text { serviço }\end{array}$ & $\begin{array}{l}\text { 1. Participa ativamente da definiçãa de necessidades do serviço para a melhoria da } \\
\text { qualidade da assistência cirúrgica prestada aos pacientes oncológicos. }\end{array}$ \\
\hline \multirow{3}{*}{$\begin{array}{l}2 \text { - Intervém nos } \\
\text { problemas da } \\
\text { organização e da } \\
\text { operacionalização } \\
\text { do serviço }\end{array}$} & $\begin{array}{l}\text { 1. Mobiliza, com base na melhor relação custo-efetividade, os recursos disponíveis de forma } \\
\text { a contribuir para a resolução dos problemas identificados na organização e na } \\
\text { operacionalização do cuidado cirúrgico aos pacientes oncológicos; }\end{array}$ \\
\hline & $\begin{array}{l}\text { 2. Organiza fluxo e agendamento de pacientes, segundo prioridades ordenadas conforme } \\
\text { critérios de estadiamento clínico, avaliação de risco cirúrgico e de progressão de doença, } \\
\text { complexidade do ato cirúrgico, estimativas de tempos de marcação e de atendimento, bem } \\
\text { como de fatores ligados às possibilidades de acesso do paciente ao serviço; }\end{array}$ \\
\hline & $\begin{array}{l}\text { 3. Participa ativamente do planejamento e da organização do trabalho da equipe } \\
\text { multidisciplinar responsável pela execução dos procedimentos cirúrgicos, assumindo a } \\
\text { liderança, sempre que necessário. }\end{array}$ \\
\hline \multirow[t]{3}{*}{$\begin{array}{l}3 \text { - Monitora e } \\
\text { avalia resultados no } \\
\text { cuidado oncológico } \\
\text { do serviço }\end{array}$} & $\begin{array}{l}\text { 1. Analisa o processo de codificação e registro em prontuários e instrumentos de gestão } \\
\text { hospitalar de procedimentos clínicos e cirúrgicos com base nos critérios de codificação em } \\
\text { cirurgia oncológica, considerando sua importância para a correta remuneração dos serviços } \\
\text { prestados e para a avaliação de qualidade do serviço; }\end{array}$ \\
\hline & $\begin{array}{l}\text { 2. Monitora e avalia metas e resultados alcançados segundo critérios e indicadores de } \\
\text { qualidade e de produção em assistência oncológica cirúrgica hospitalar; }\end{array}$ \\
\hline & $\begin{array}{l}\text { 3. Participa da avaliação e da proposição de iniciativas para otimizar e racionalizar a } \\
\text { distribuição de recursos materiais e financeiros entre os diversos setores da atenção } \\
\text { oncológica na instituição. }\end{array}$ \\
\hline
\end{tabular}


Área de Competência 3: Educação

\begin{tabular}{|c|c|}
\hline Ações & Desempenhos (atividades qualificadas) \\
\hline \multirow{3}{*}{$\begin{array}{l}\text { 1- Identifica } \\
\text { necessidades de } \\
\text { aprendizagem } \\
\text { individuais e } \\
\text { coletivas }\end{array}$} & $\begin{array}{l}\text { 1. Identifica suas necessidades de aprendizagem, bem como da equipe multidisciplinar, frente } \\
\text { ao dinamismo da produção de conhecimento nas diferentes áreas da oncologia, visando à } \\
\text { otimização do tratamento e orientação do paciente com doença tumoral e seus familiares; }\end{array}$ \\
\hline & $\begin{array}{l}\text { 2. Realiza busca efetiva e ativa em sistemas de informações e em bases de dados, bem como } \\
\text { participa em eventos técnico-científicos na área da oncologia para suprir suas necessidades } \\
\text { de educação continuada; }\end{array}$ \\
\hline & $\begin{array}{l}\text { 3. Identifica necessidades de aprendizagem de pós-graduandos e graduandos, reconhecendo } \\
\text { a dimensão educativa de seu trabalho nos diferentes cenários da ação profissional como } \\
\text { cirurgião oncológico e o caráter educacional da discussão dos problemas no serviço. }\end{array}$ \\
\hline \multirow{3}{*}{$\begin{array}{l}2 \text { - Organiza } \\
\text { atividades de } \\
\text { ensino- } \\
\text { aprendizagem }\end{array}$} & $\begin{array}{l}\text { 1. Comunica adequadamente em espaços de divulgação técnico-científica, divulgando os } \\
\text { achados da produção e da avaliação crítica de conhecimento no campo da cirurgia } \\
\text { oncológica; }\end{array}$ \\
\hline & $\begin{array}{l}\text { 2. Organiza e participa de atividades de ensino-aprendizagem em serviço, promovendo a } \\
\text { dimensão educativa de sessões clínicas e visitas de enfermaria, explorando estes espaços } \\
\text { como momentos de aprendizagem da equipe multiprofissional para a melhoria da qualidade } \\
\text { da assistência oncológica; }\end{array}$ \\
\hline & $\begin{array}{l}\text { 3. Participa da difusão de informações para a promoção da saúde, para a prevenção e } \\
\text { controle do câncer junto aos pacientes, cuidadores, familiares, equipes multiprofissionais e } \\
\text { comunidade, reconhecendo a diversidade de representações sobre o câncer e a necessidade } \\
\text { do uso de diferentes linguagens. }\end{array}$ \\
\hline
\end{tabular}

\section{Área de Competência 4: Pesquisa}

\begin{tabular}{|l|l|}
\hline \multicolumn{1}{|c|}{ Ações } & \multicolumn{1}{c|}{ Desempenhos (atividades qualificadas) } \\
\hline $\begin{array}{l}\text { 1- Avalia e produz } \\
\text { conhecimento na } \\
\text { área da oncologia }\end{array}$ & $\begin{array}{l}\text { 1. Emprega ferramentas de avaliação crítica do conhecimento para verificar a pertinência da } \\
\text { adoção de novas condutas clínicas e cirúrgicas em oncologia; }\end{array}$ \\
\cline { 2 - 2 } & $\begin{array}{l}\text { 2. Participa ativamente de iniciativas de produção de conhecimento e de avaliação } \\
\text { tecnológica em saúde, orientando-se por princípios éticos e por sólida compreensão do } \\
\text { método científico. }\end{array}$ \\
\hline
\end{tabular}


Apêndice C. Componentes do Grupo de Trabalho de Instituições Formadoras

\begin{tabular}{|l|c|c|}
\hline \multicolumn{1}{|c|}{ Instituição } & Responsável pela \\
Residência Médica & Origem \\
\hline Fund.Antonio Prudente - A.C.Camargo & Samuel Aguiar & São Paulo \\
\hline $\begin{array}{l}\text { Fundação Centro de Controle de Oncologia do } \\
\text { Amazonas - FCECON }\end{array}$ & Sócrates Lote Oliveira & Manaus \\
\hline Fund. Pio XII - Barretos & Carlos Augusto R. Veo & S.J.Rio Preto \\
\hline Hospital Araújo Jorge & Luiz de Paula S. Junior & Goiânia \\
\hline Hospital das Clínicas Porto Alegre & Alceu Migliavaca & Porto Alegre \\
\hline Hosp.Univ.Evangélico de Curitiba & João Calos Simões & Furitiba \\
\hline Instituto de Câncer do Ceará & Fabio Landim & Rio de Janeiro \\
\hline Instituto Nac. Câncer - INCA & Eliana Claudia O. Ribeiro & Rio de Janeiro \\
\hline Instituto Nac. Câncer - INCA & José Adalberto F. Oliveira & Rio de Janeiro \\
\hline Instituto Nac. Câncer - INCA & Simone Vincent & Rio de Janeiro \\
\hline Instituto Nac. Câncer - INCA & Jurandyr Almeida Dias & Rio de Janeiro \\
\hline Instituto Nac. Câncer - INCA & Marisol Pensado Pazos & Porto Alegre \\
\hline Sta Casa Porto Alegre & Antonio Kalil & Natal \\
\hline Liga Norte-Riograndense Contra o Câncer & Elio José Silveira S.Barreto & Curitiba \\
\hline Hospital Erasto Gaertner & Flavio Daniel S. Tomasich & \\
\hline
\end{tabular}

